\title{
Sentetik Açıklıkıı Radar verilerinin Taşkın Çalışmalarında Kullanılması: Berdan Ovası Taşkını
}

\author{
Mehmet Ali AKGÜL ${ }^{1 *}$ \\ ${ }^{1}$ Devlet Su İşleri 6.Bölge Müdürlüğü, Havza Yönetimi, İzleme ve Tahsisler Şube Müdürlüğü, Adana \\ (mali.akgul@dsi.gov.tr) ORCID ID 0000 -0002 - 5517 - 9576
}

\begin{abstract}
$\ddot{O} \mathbf{z}$
Taşkın alanının tespit edilmesi çalışmalarında uzaktan algılama yöntemleri sıklıkla kullanılmaktadır. Yağışı meydana getiren bulutların taşkın anında ve sonrasında da devam etmesi optik görüntüleme yapan uyduların taşkın alanını tespit etmesinde yetersiz kalmasına sebep olmaktadır. Bu eksiklik ise radar uyduları ile giderilebilmektedir. Bu çalışmada, taşkın alanının tespit edilmesi ve taşkın sürecinin izlenmesi amacıyla SAR (Sythetic Aperture Radar, Sentetik Açıklıklı Radar) uydularından olan Sentinel-1 uydusunun kullanılma olanakları araştırılmıştır.

Çalışma, Aralık 2016-Ocak 2017 tarihleri arasında Mersin ilinde meydana gelen taşkında en çok etkilenen bölgelerden biri olan, Berdan ovasında mevcut eski Aynaz bataklığında yürütülmüştür. Sentinel-1 uydusuna ait, 24.12.2016-28.01.2017 tarihleri arasında bölgeyi kapsayan 12 adet verinin tamamı eşik değeri yöntemi kullanılarak analiz edilmiş ve taşkının kapladığı alanlar hesaplanmıştır. Ayrıca fotogrametrik haritalardan bu çalışma için üretilen sayısal arazi modeli (SAM) yardımıyla çalışma alanının kot-alan-hacim cetveli çıkarılmıştır. Bu grafik ve hesaplanan taşkın alanları yardımı ile uydu verisinin olduğu her gün için taşkın hacimleri ve taşkın kotları üretilmiş ve grafiklendirilmiştir. Çalışmada, taşkının yayılımının en büyük olduğu tarih 05.01.2017 olarak tespit edilmiş, bu tarihte taşkın alanı 715.02 ha ve taşkın hacmi ise $4.23 \mathrm{hm}^{3}$ olarak bulunmuştur.

Çalışma neticesinde, taşkın anında ve sonrasında mevcut kötü hava şartlarından etkilenmeyen Sentinel-1 uydu verilerinin taşkın çalışmalarında kullanılabileceği sonucunu varılmıştır.
\end{abstract}

Anahtar Kelimeler: Uzaktan Algılama, SAR, Taşkın.

\section{Use of Synthetic Aperture Radar Data in Flood Studies: Berdan Plain Flood}

\begin{abstract}
Remote sensing methods are frequently used in the studies of determining the flood area. Clouds bringing rain to the flood continue at the moment of flood and afterwards, causes optical saturating satellites to fail to detect the flood area. This deficiency can be eliminated with radar satellites. In this study, the possibilities of using the Sentinel-1 satellite from SAR (Sythetic Aperture Radar) satellites were investigated in order to determine the flood area and monitor the flood process.

The study was carried out in the old Aynaz marsh in Berdan plain which is one of the most affected provinces in Mersin province between December 2016 and January 2017. The areas covered by the flood were calculated by analyzed using threshold method all 12 data from the Sentinel-1 satellite, between December 24, 2016 and January 1, 2017, covering the region. In addition, a level-area-volume chart of the study area was obtained from the photogrammetric maps with the aid of the digital elevation model (SAM) produced for this study. With the aid of this graph and calculated flood areas, flood volumes and flood levels are produced and charted
\end{abstract}

* Sorumlu Yazar 
for each day of satellite data. In the study, the date of the flood spread was found to be the date of 05.01.2017, where the flood area was 715.02 ha and the flood volume was $4.23 \mathrm{hm}^{3}$.

As a result of the study, Sentinel-1 satellite datas, which are not affected by the current bad weather conditions at the time of flood and afterwards, can be used for flood operations.

Keywords: Remote Sensing, SAR, Flood.

\section{GİRIŞ}

Taşkın, insan ırkının bildiği su kaynaklı en büyük doğal felakettir ve insani, maddi ve ekolojik maliyetleri sürdürülebilir kalkınma için yıkıcı olabilir. Taşkınlar yılda yaklaşık 520 milyon insanı etkilemekte ve 25000 ölümle sonuçlanmaktadır. Su kaynaklı diğer felaketlerin yanı sıra, dünya ekonomisine y1lda 50-60 milyar dolarlık bir maliyete sahiptir (Teegavarapu, 2012).

Küresel iklim değişikliğinin en büyük etkilerinden olan taşkınların oluş sıklığı ve etkilediği alanların artması taşkın haritalarını önemli hale getirmektedir.

Taşkın alanlarının kapsadığı alanın büyüklüğü, taşkın anındaki hava şartları, taşkın süresinin az olması ve taşkın haritasına duyulan aciliyet sebebiyle yersel ölçümler bu tür çalışmalarda yetersiz kalmakta, bu eksiklik ise uzaktan algılama çalışmaları ile giderilebilmektedir.

Taşkını meydana getiren yağışların taşkın anında ve sonrasinda da devam etmesi, bulutluluk konusunda hassas olan optik görüntüleme yapan uyduların kullanılamamasına sebep olmaktadır. Her türlü hava şartında, gece-gündüz görüntüleme yapma yeteneğine sahip radar uyduları, taşkın çalışmalarında optik uyduların eksikliğini kapatabilmektedir. Şekil 1'de Avrupa Uzay Ajansı'na (ESA) ait optik görüntüleme yapan Sentinel-2 uydusu ile Sentinel-1 uydusunun aynı güne ait Aynaz bataklığındaki taşkın durumu görülmektedir.

Çalışmanın yapıldığı 24.12.2016-28.01.2017 tarihleri arasında ücretsiz erişilebilen Landsat 8 uydusuna ait 6 adet ve Sentinel-2 uydusuna ait 6 adet olmak üzere 12 adet optik uydu verisinin tamamında bulutluluk sorunu olduğu için ayrıca bir doğrulama yapılamamıştır.

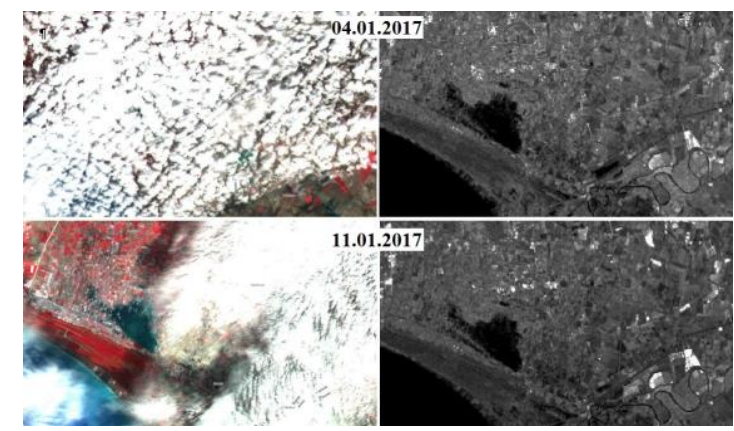

Şekil 1. Sentinel-2 (RGB:843;Sol) ve Sentinel1 (Sağ)

Clement ve ark. (2017) Aralık 2015-Ocak 2016 tarihlerinde Yorkshire/İngiltere' de meydana gelen taşkını Sentinel-1 uydu verisinin $\mathrm{VH}$ ve $\mathrm{VV}$ polarizasyon modlarını kullanarak analiz etmişlerdir. Sentinel-2 uydusuna ait optik görüntüleri kullanarak çalışmayı doğrulamışlardır. Her iki modda da \%97 doğruluk bulmalarına rağmen $\mathrm{VV}$ modunun VH modundan daha az yanlış sınıflama yaptığını tespit etmişlerdir.

Čotar ve ark. (2016) Slovenya ve yakın çevresindeki su kütlelerini haritalamak için Sentinel-1 uydu verisini kullanarak bir sistem uygulamışlardır. Çalışmalarında su ve karanın ayrılmasında Otsu' nun eşik değer yöntemini kullanmışlardır. Ayrıca Sentinel-1 uydusunun VV polarizasyon modunun daha güvenilir ve daha doğru sonuçlar verdiğini bulmuşlardır.

Çalışma alanı tarihsel süreç içerisinde birçok değişim göstermiştir. Eski bir liman kenti olan Tarsus için Piri Reis, Kitab-1 Bahriye' de deniz kenarından 3 mil (yaklaşık $5.5 \mathrm{~km}$ ) kadar içeride olduğunu belirtmekte şimdi ise denizden $18 \mathrm{~km}$ kadar içeride bulunmaktadır. Ayrıca nehrin ağzında bir boğaz olduğu, bu boğaza sandalların girdiğgi belirtilmiştir (Piri Reis, 1525;Şekil 2a). 

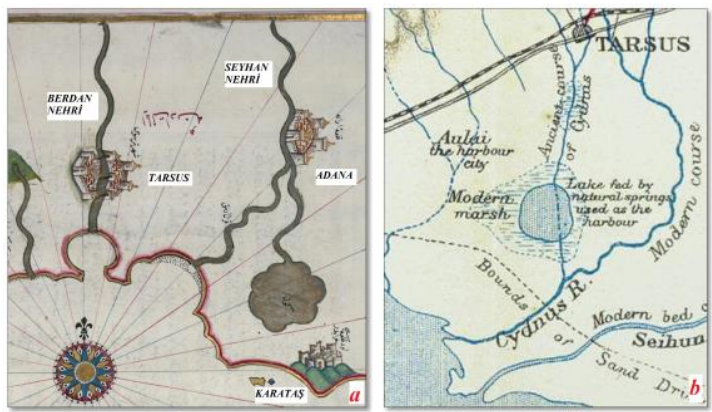

Şekil 2. Piri Reis, 1525 (a), Ramsay, 1903 (b)

Berdan ve Seyhan Nehirlerinin getirdiği alüvyonlar sonucunda bu boğazın deniz ile bağlantısı kesilmiştir. $\mathrm{Bu}$ oluşum sırasında Berdan Nehri üzerinde Rhegma adı verilen bir iç göl meydana gelmiş, bu gölü besleyen Berdan Nehrinin yatağının değiştirilmesi sonucunda ise göl kuruyarak Aynaz bataklığına dönüșmüștür (SSekil 2b). Devlet $\mathrm{Su}$ İşleri (DSI) tarafindan 1958 yılında başlayan Aynaz bataklığını kurutma çalışmaları 1969 yılında neticelendirilmiş (Resmi Gazete, 1969), bataklık kurutularak tarım arazisine çevrilmiş ve Berdan Ovası sulamasının bir parçası haline getirilmiştir.

Çalışma alanında IECO (International Engineering Company Inc.) firmas1 tarafindan 1966 yılında bir rapor hazırlanmıştır. Bu raporda, "bölgede bulunan köylüler tarafindan yıl içerisinde arazilerinin $2 \mathrm{~m}$ derinliğe kadar taşkın sularıyla istila edildiği bildirilmiştir" denilmektedir (IECO, 1966; Şekil 3). Bu çalışmada ise taşkının en büyük alana ulaştı̆̆ 1 05.01.2017 tarihinde, en derin yerinde $2.39 \mathrm{~m}$ olarak hesaplanarak bu bilginin de doğru olduğu görülmüştür.

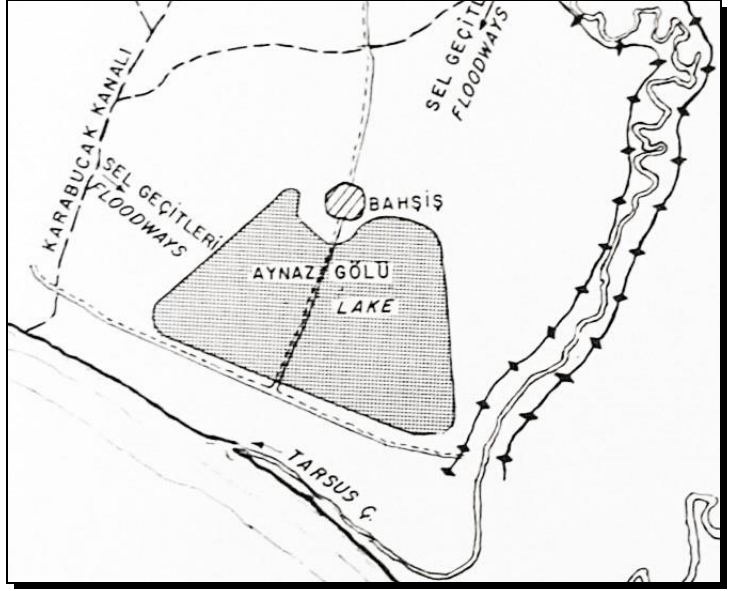

Şekil 3. Eski Aynaz Gölü (IECO, 1966)

$\mathrm{Bu}$ çalışmada, Sentinel-1 uydu verileri kullanılarak Aralık 2016-Ocak 2017 tarihleri arasında yaşanan Mersin taşkınında en çok etkilenen alanlardan biri olan eski Aynaz bataklığındaki taşkın alanı incelenmiştir.

\section{YÖNTEM}

\subsection{Materyal}

Çalışma alanı, Berdan Nehrinin Akdeniz'e döküldüğü yerin batısında, Tarsus ilçesinin ve Berdan Ovasının en güney kısmında bulunan, Aynaz bataklığının kurutulmasıyla oluşan ve yoğun olarak tarım yapılan bir bölgedir (Şekil 4).

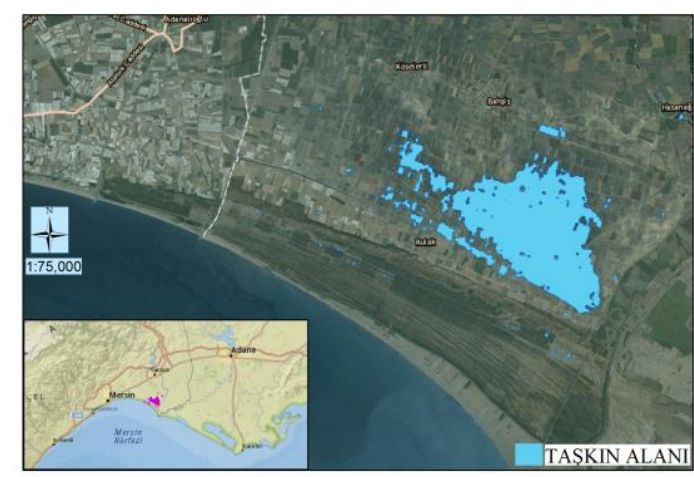

Şekil 4. Çalışma Alanı

Bu çalışmada, 3 Nisan 2014 tarihinde göreve başlayan Sentinel-1A ve 25 Nisan 2016 tarihinde göreve başlayan Sentinel-1B uyduları kullanılmıştır. Sentinel-1 uyduları, Avrupa Komisyonu (EC) ve Avrupa Uzay Ajans1 
(ESA)'nın ortak girişimi olan Copernicus programı dahilinde Avrupa Radar Rasathanesi uydularındandır. Daha önce GMES (Global Monitoring for Environment and Security) olarak bilinen Copernicus programı, çevre ve güvenlik ile ilgili bilgi hizmetlerinin uygulanması için geliştirilen bir Avrupa girişimidir (Sentinel-1 Team,2013).

Ana görevleri arasında ormanların, su kaynaklarının, toprakların ve tarımsal alanların izlenmesi, doğal afet durumunda acil durum haritalarının üretilmesi, denizlerdeki çevresel faktörlerin izlenmesi ve iklim değişikliğinin izlenmesi gösterilebilir. SAR, bulut örtüsünün veya aydınlatma eksikliğinin engellediği dalga boylarında çalışma avantajına sahiptir ve tüm hava koşullarında, gece veya gündüz bir yerden veri toplayabilir. Sentinel-1, C-SAR aleti ile güvenilir, tekrarlanan geniş alan izleme imkânı sunar (Sentinel-1 Team,2013).

Sentinel-1 uyduları, farklı çözünürlük ve tarama genişliği olan dört özel modda çalışan C-band (5.405 GHz) görüntüleme özelliğini içerir (Tablo 1).

Tablo 1. Sentinel-1 Görüntüleme Modları (Sentinel-1 Team, 2013)

\begin{tabular}{|c|c|c|c|c|}
\hline Mod & $\begin{array}{l}\text { Tar. Ge } \\
\text { n. }(\mathrm{km})\end{array}$ & $\begin{array}{l}\text { Çözn. } \\
\text { (SLC) } \\
(\mathrm{m}) \\
\end{array}$ & $\begin{array}{l}\text { Çözn. } \\
\text { (GRD) } \\
(\mathrm{m}) \\
\end{array}$ & $\begin{array}{l}\text { Polar. } \\
\text { (H:Yt } \\
\text { V:Dk) }\end{array}$ \\
\hline Strip Map (SM) & 80 & $5 * 5$ & $23 * 23$ & $\begin{array}{l}\mathrm{HH}+\mathrm{HV}, \\
\mathrm{VH}+\mathrm{VV}, \\
\mathrm{HH}, \mathrm{VV}\end{array}$ \\
\hline Interferometric & 250 & $5 * 20$ & $20 * 22$ & $\mathrm{HH}+\mathrm{HV}$, \\
\hline $\begin{array}{l}\text { Wide Swath } \\
\text { (IW) }\end{array}$ & & & & $\begin{array}{l}\text { VH+VV, } \\
\mathrm{HH}, \mathrm{VV}\end{array}$ \\
\hline $\begin{array}{l}\text { Extra-Wide } \\
\text { Swath (EW) }\end{array}$ & 400 & $20 * 40$ & $50 * 50$ & $\begin{array}{l}\mathrm{HH}+\mathrm{HV}, \\
\mathrm{VH}+\mathrm{VV}, \\
\mathrm{HH}, \mathrm{VV}\end{array}$ \\
\hline $\begin{array}{l}\text { Wave-Mode } \\
\text { (WM) }\end{array}$ & $20 * 20$ & $5 * 5$ & - & HH, VV \\
\hline
\end{tabular}

Her modda, Level-0 Raw, Level-1 SLC (Single Look Complex), Level-1 GRD (Ground Range Detected) ve Level-2 OCN (Ocean) olmak üzere 4 ayrı veri üretilmektedir.

Level-1 GRD verisinin tam, yüksek ve orta çözünürlükte üç ayrı modu bulunmaktadır. Bu çözünürlük ve piksel aralığı çok-bakışın (multi-look) gerçekleştirilen sayısına bağlıdır (Sentinel-1 Team, 2013).

$\mathrm{Bu}$ çalışmada, yüksek çözünürlüklü Level-1 GRD verisinin IW modu kullanılmıştır (Tablo 2). Bu veri WGS84 koordinat sisteminde, çokbakışlandırılmış (multi-looked) ve zemindeki mesafeyi yansitan, odaklanmış SAR verilerinden oluşur (Sentinel-1 Team, 2013).

Tablo 2. Yüksek Çözünürlüklü Level-1 GRD Görüntüleme Modları (Sentinel-1 Team, 2013)

\begin{tabular}{cccc}
\hline Mod & $\begin{array}{c}\text { Çözünürlük } \\
(\mathrm{m})\end{array}$ & $\begin{array}{c}\text { Piksel Aralığ } \\
(\mathrm{m})\end{array}$ & $\begin{array}{c}\text { Bakış } \\
\text { Sayıs }\end{array}$ \\
\hline SM & $23 * 23$ & $10 * 10$ & $6 * 6$ \\
IW & $20 * 22$ & $10 * 10$ & $5 * 1$ \\
EW & $50 * 50$ & $25 * 25$ & $3 * 1$ \\
\hline
\end{tabular}

Her farklı uygulama için Sentinel-1 uydularının farklı modları kullanılmaktadır. Taşkın alanlarının görüntülenmesi için en uygun modlar SM ve IW modlarıdır. SM modu acil durum yönetim eylemlerini desteklemek için yalnızca istisnai durumlarda kullanılmakta olup arazideki uygulamaların çoğunda IW modu kullanılmaktadır (Sentinel-1 Team, 2013).

Çalışmada polarizasyon olarak VV modu kullanılmıştır. VV modu, uydu üzerinde bulunan alıc1 ve verici antenlerinin ikisinin de dikey (Vertical) konumlandığ 1 moddur. Yapılan çalışmalarda, SAR verileri ile taşkın alanı tespit çalışmalarında diğer polarizasyon modlarına göre daha iyi sonuç verdiği görülmüştür (Manjusree ve ark., 2012).

Autocad Civil 3D 2016 programı yardımıyla fotogrametrik yöntemlerle üretilmiş halihazır haritalardan çalışma alanının sayısal arazi modeli (SAM) üretilmiştir (Şekil 5). 


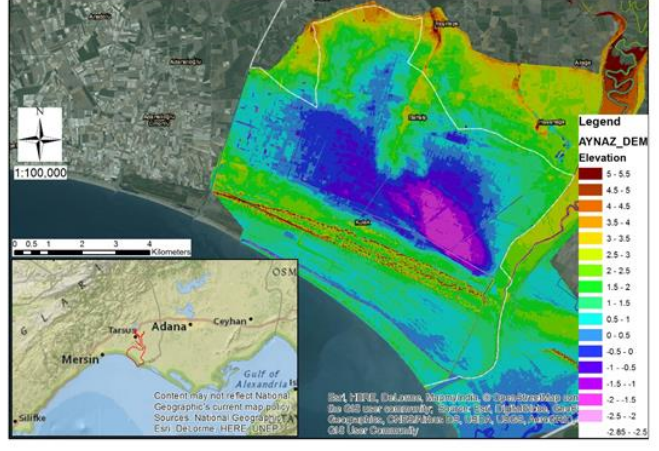

Şekil 5. Sayısal Arazi Modeli

Yine aynı program içerisinde bulunan Analyze/Design/Stage Storage modülü kullanılarak SAM'nin her bir kotuna karşı1lık gelen alan ve hacim değerleri hesaplanmıştır (Autodesk Inc., 2016). Çalışma alanının en düşük ve en yüksek kotu arasında $2.39 \mathrm{~m}$ gibi düşük bir değer olduğu için alan ve hacim değerleri $10 \mathrm{~cm}$ kot aralığında hesaplanmıştır.

Kot, hesaplanan alan ve hacim değerleri kullanılarak kot-alan-hacim cetveli üretilmiştir.

Baraj ve gölet gibi depolamalı su yapılarının planlama, projelendirme ve işletme çalışmaları için çok önemli olan bu cetveller çalışma alanının eski bir göl olması dolayısıyla bu çalışma için de üretilmiş ve kullanılmıştır.

Taşkın alanlarına karşılık gelen kot ve hacimler, kot-alan-hacim cetvelinden enterpole edilerek bulunmuştur.

\subsection{Yöntem}

SAR verilerinde, optik uzaktan algilama verilerinden farklı olarak, görsel yorumlamada güçlüğe neden olan benek etkisi, topoğrafik etki ve yüzey pürüzlülügü etkisi barındırır. $\mathrm{Bu}$ nedenle SAR verileri ile çalışmaya başlamadan önce gerekli kalibrasyonun ve düzeltmelerin yapılması şarttır.

Çalışma Şekil 6'da verilen akış diyagramına göre yapılmıştır.

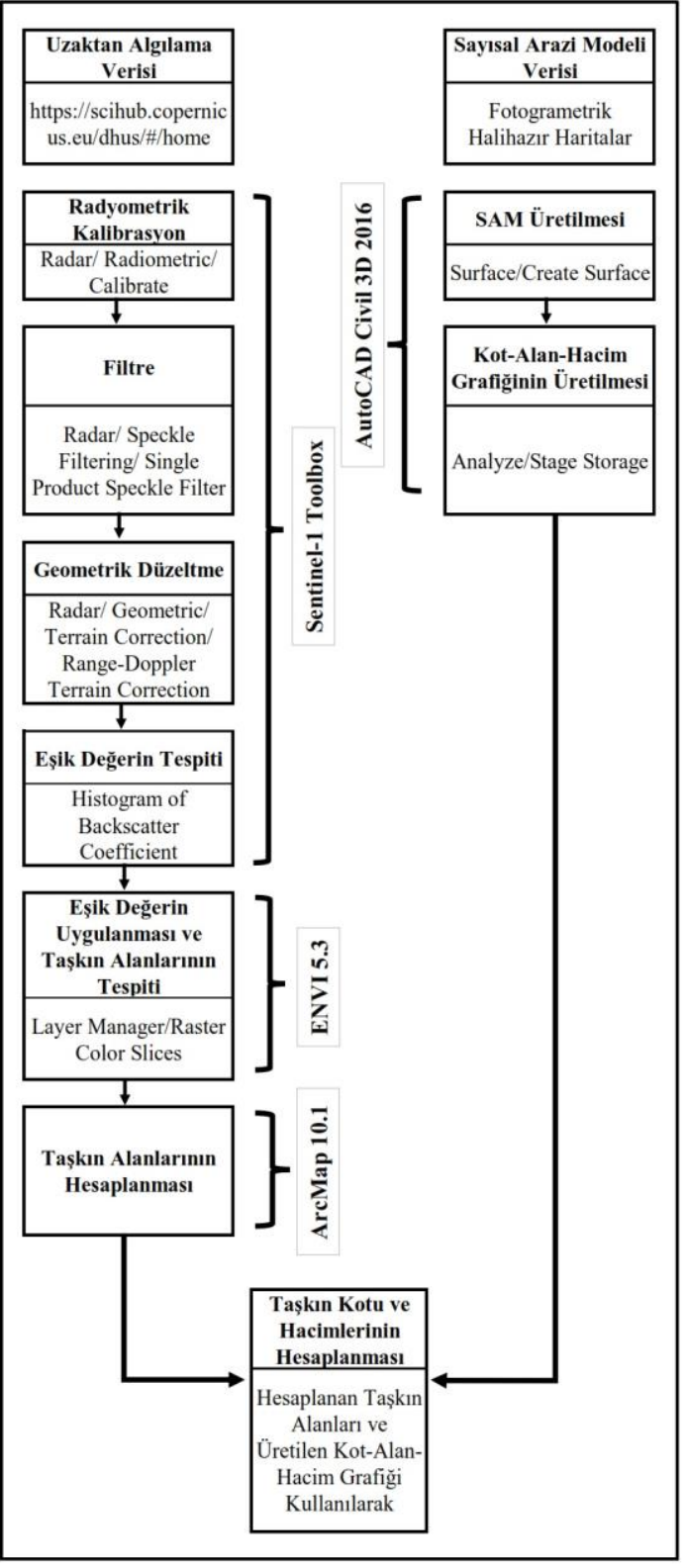

Şekil 6. Çalışmanın Akış Diyagramı

Radyometrik kalibrasyon, farklı sensörlerle elde edilen radar görüntülerinin karşılaştırılması için veya aynı sensörün farklı modlarda üretilmiş, farklı işlemcilerle işlenmiş görüntülerinin karşılaştırılması için gereklidir. SAR görüntülerinin radyometrik kalibrasyonu sonucunda Sigma0 değerleri hesaplanmıştır.

SAR görüntülerinde, sinyale bağımlı olarak benek etkisi oluşur ve bunun giderilmesi için filtre uygulanması gerekir. Çalışmada, cisimlerin kenarlarını, doğrusal özelliklerini, nokta hedefleri ve dokularını koruyarak bu 
etkiyi ortadan kaldıran Lee filtresi kullanılmıştır (Lee, 2009).

Geometrik düzeltme ile SAR verisinde meydana gelen geometrik bozulmalar SAM kullanarak düzeltilir ve bir harita projeksiyonlu veri üretilir. $\mathrm{Bu}$ çalışmada geometrik düzeltmeler için SRTM3 (USGS, 2006) SAM'i kullanılmış, WGS84-UTM projeksiyonunda veri üretilmiştir.

Aktif bir uzaktan algılama yöntemi olan SAR ile edilen veriler, gönderilen dalgaların cisimlere çarptıktan sonra dönen miktarının uydu tarafından algılanması ile oluşur. Eğer hedef cisim durgun su yüzeyi gibi tam yansıma yapan bir yüzey ise daha az veri geri döneceğinden veya hiç dönmeyeceğinden dolayı bu bölgeler uydu verisinde siyah ve tonları olarak gözlenir (Şekil 7a). Buna karşın toprak yüzeyi ve bitki örtüsü dağınık yansıma yapacağından dolayı daha çok veri geri dönecektir. Bu bölgeler uydu verisinde parlak tonlarda görülürler (Şekil 7b).
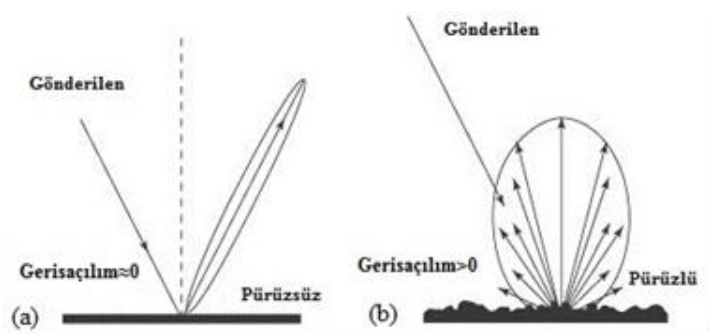

Şekil 7. Pürüzlülük ile Gerisaçılım Arasındaki İlişki (Onstott ve Shuchman, 2004)

Yüzey sularını SAR görüntüleri ile haritalamak için en çok kullanılan yöntem eşik değeri yöntemidir. $\mathrm{Bu}$ yöntemde, bir yoğunluk görüntüsünde belirli bir eşik değerinden daha düşük bir gerisaçılım katsayısına sahip tüm pikseller su olarak eşleştirilir (Hess ve ark., 1995;Henry ve ark., 2006). Bu teknik, hızlı ve ucuz sonuçlar üretmek için kullanışlıdır (Martinis ve ark., 2009), ancak sadece tam yansıma yapan sakin açık su için uygundur (Pulvirenti ve ark., 2011).

Çalışma sahasının sadece tarım yapılan bir bölge olması, yerleşim yeri veya herhangi bir yap1 bulunmaması, taşkın alanıyla karışabilecek az gerisaçılım yapan asfalt yol vb. detayların olmamasından dolayı çalışmada eşik değeri yöntemi seçilmiştir.
Her bir Sigma0 görüntüsünün gerisaç1lım katsayılarına ait histogramları hazırlanmıştır. Çift tepe noktasına sahip bu histogramlar üzerinde düşük olan taşkın alanını, yüksek olan ise taşkın olmayan alanı göstermektedir (Şekil $8)$.

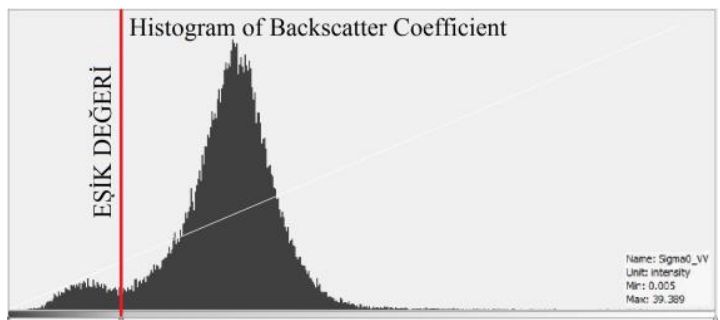

Şekil 8. 05.01.2017 Tarihli Görüntüye ait Gerisaçılım Katsayılarının Histogramı ve Eşik Değeri

Histogram üzerinde bu iki tepe arasında kalan ve eşik değer olarak alınan gerisaçılım katsayıs1 değeri Otsu metoduna (Otsu, 1979) dayalı gri-seviye histogram analizi kullanılarak her bir görüntü için ayrı ayrı hesaplanmıştır.

Ayıca Sigma0 görüntüsü üzerinde taşkın alanı ve taşkından etkilenmeyen alanı kapsayacak şekilde profil alınmış eşik değerin doğruluğu bu profil üzerinde de kontrol edilmiştir (Şekil 9).
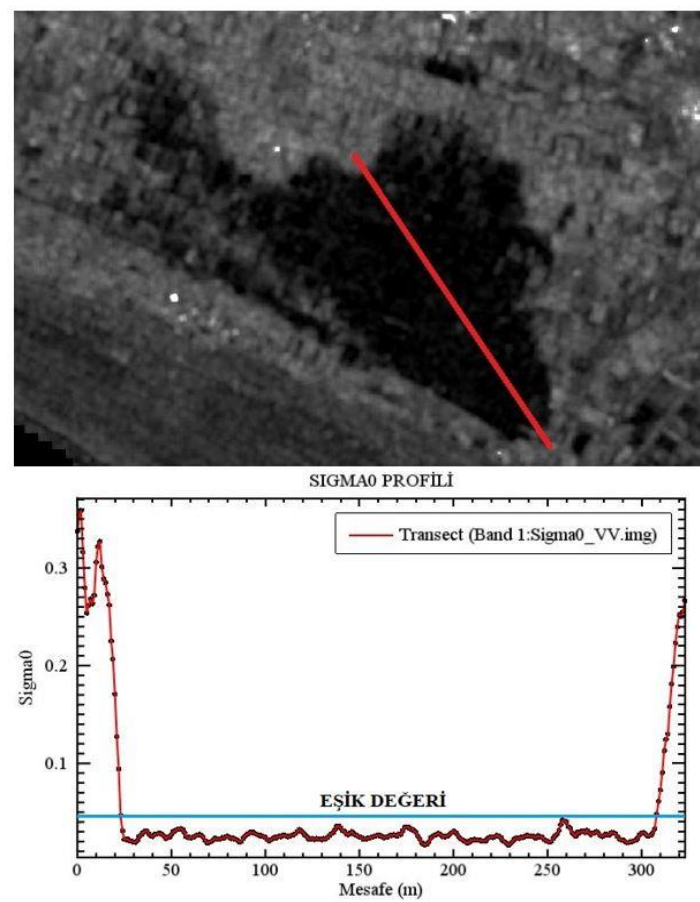

Şekil 9. 05.01.2017 Tarihli Görüntüye ait Sigma0 Profili ve Eşik Değeri 
Eşik değer bulunduktan sonra her bir uydu görüntüsüne uygulanarak taşkından etkilenen alanlar tespit edilmiştir.

\section{BULGULAR}

Taşkın başlamadan önce ve taşkın sona erdikten sonraki zaman aralığında mevcut 12 adet Sentinel-1 uydu verisinin tamamı analiz edilmiştir (Şekil 10). Çalışmada, Sentinel-1 uydusunun IW modunda, yüksek çözünürlüklü, Level-1 GRD seviyesindeki VV verileri kullanılmıștır. Veriler analiz edilmeden önce gerekli radyometrik kalibrasyon ve geometrik düzeltmeler Sentinel-1 toolbox programı (ESA, 2015), taşkın alanının tespit edilmesi için ise ENVI 5.3 yazılımı (Canty, 2014) kullanılmıştır.

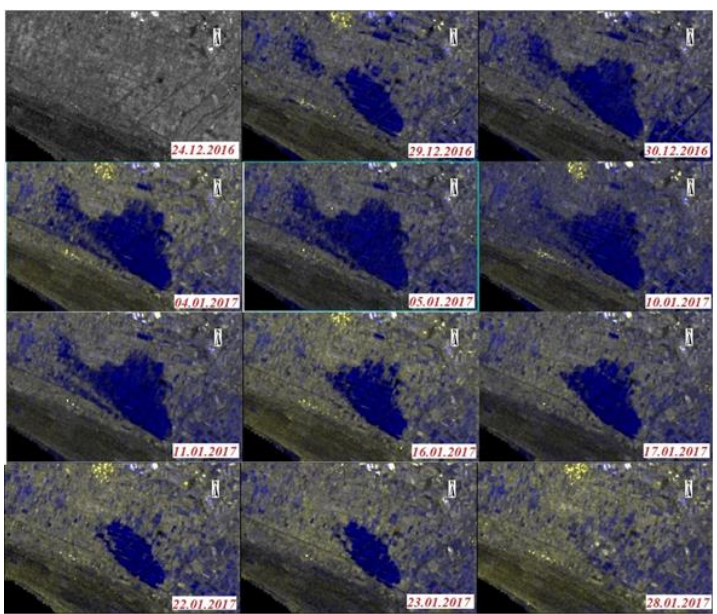

Şekil 10. Taşkın Alanı Zamansal Değişimi

Taşkın alanları ve hazırlanan kot-alan-hacim cetvellerinden enterpole edilerek hesaplanan taşkın kotları ve hacimleri Tablo 3'de verilmiștir.

Tablo 3. Taşkın Alanı, Kotu ve Hacmi

\begin{tabular}{llll}
\hline Tarih & Alan (ha) & Kot $(\mathrm{m})$ & Hacim $\left(\mathrm{hm}^{3}\right)$ \\
\hline 24.12 .2016 & 0 & -2.85 & 0 \\
29.12 .2016 & 417.16 & -0.87 & 2.13 \\
30.12 .2016 & 519.58 & -0.71 & 2.84 \\
04.01 .2017 & 559.98 & -0.65 & 3.12 \\
\hline
\end{tabular}

\begin{tabular}{llll}
\hline Tarih & Alan (ha) & Kot $(\mathrm{m})$ & Hacim $\left(\mathrm{hm}^{3}\right)$ \\
$\mathbf{0 5 . 0 1 . 2 0 1 7}$ & $\mathbf{7 1 5 . 0 2}$ & $\mathbf{- 0 . 4 6}$ & $\mathbf{4 . 2 3}$ \\
10.01 .2017 & 516.81 & -0.72 & 2.82 \\
11.01 .2017 & 652.78 & -0.51 & 3.76 \\
16.01 .2017 & 391.79 & -0.91 & 1.96 \\
17.01 .2017 & 423.15 & -0.86 & 2.17 \\
22.01 .2017 & 308.95 & -1.06 & 1.38 \\
23.01 .2017 & 257.63 & -1.21 & 1.02 \\
28.01 .2017 & 9.86 & -2.17 & 0.02 \\
\hline
\end{tabular}

Taşkın, 05.01.2017 tarihinde $4.23 \mathrm{hm}^{3}$ taşkın hacmi ile en büyük değerini almıstır. Bu değer birçok göletten daha büyük bir değerdir. Örneğin çalışma alanının $35 \mathrm{~km}$ kuzeyinde yer alan ve yapımı devam eden 983 ha alanı sulayacak olan Tarsus Karaevli göletinin 4.17 $\mathrm{hm}^{3}$ aktif depolama hacmine sahip olacağ düşünüldüğünde taşkının boyutu ve büyüklüğü daha iyi anlaşılmaktadır (DSİ, 2016).

Taşkın alanı ile yağış olan günler ve miktarı arasındaki ilişki Şekil 11'de gösterilmiştir. Yağış değerleri çalışma alanının $20 \mathrm{~km}$ kuzeyinde yer alan Berdan barajında mevcut bulunan Berdan MGİ' den (Meteoroloji Gözlem İstasyonu) alınmıştır.

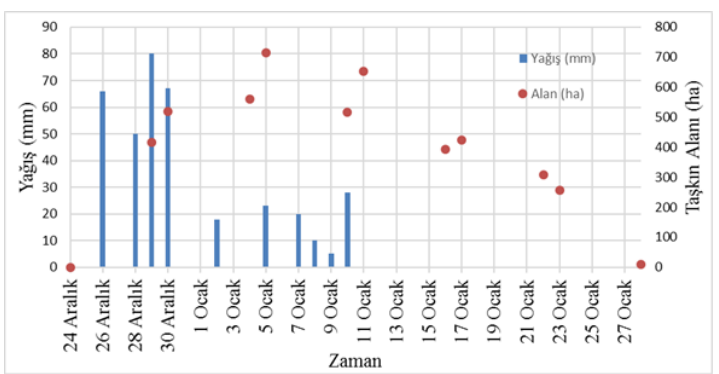

Şekil 11. Taşkına Alanı Büyüklüğü-Yağış İlişkisi Grafiği

Yağış olan gün veya ertesi gün taşkın alanının arttığı görülmektedir. 10 Ocak tarihinden sonra yağış kesilmiş, taşkın alanı da buna istinaden azalmış 28 Ocak tarihinde ise bitmiştir.

29, 30 Aralık ve 10 Ocak tarihlerinde yağış devam ederken dahi uydu verisi mevcuttur. Özellikle 29 Aralık tarihinde $80 \mathrm{~mm}$ ve 30 
Aralık tarihinde $67 \mathrm{~mm}$ gibi yoğun yağışlarda taşkın alanında bulunmak bile tehlike arz ederken taşkın alanının ve taşkın hacminin tahmin edilebilmesi çok zordur. Taşkın devam ederken, taşkının biriktiği yerin ve taşkının büyümesine neden olan engellerin tespit edilmesi, karar vericiler tarafından taşkın zararının azaltılması açısından çok önemlidir.

Ayrıca bu çalıșma kapsamında, taşkın sonrasında oluşan zararın da tespit edilmesine çalışmıştır. Bunun için sayısal kadastro verileri ile taşkının en büyük alana ulaştığı 05.01.2017 tarihindeki taşkın sınırı verisi kullanılarak, Coğrafi Bilgi Sistemi (CBS) ortamında kaç adet parselin taşkından etkilendiği hesaplanmıştır. Taşkından kısmen veya tamamen etkilenen parsel sayis1 1004 adet olmasına rağmen bunun sadece 578 âdetinin tarla niteliğinde olduğu tespit edilmiştir (Şekil 12).

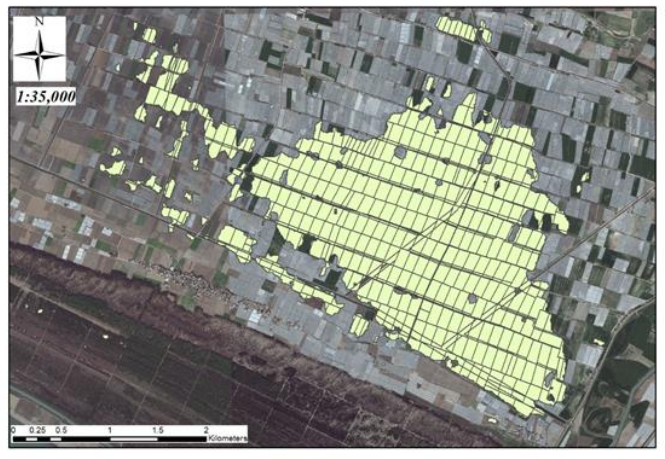

Şekil 12. Taşkından etkilenen Parseller

Taşkından kısmen veya tamamen etkilenen parsellerin tapu kayitlarında belirtilen cinslerine göre, parsel sayıs1 ve parsel alanları toplamı ise Tablo 4'de verilmektedir.

Tablo 4. Taşkından etkilenen Parsellerin İstatistikleri

\begin{tabular}{lll}
\hline Parsel Cinsi & Parsel Sayısı & Parsel Alanı (ha) \\
\hline Tarla & 578 & 605.50 \\
Kanal & 364 & 74.10 \\
Boş (Tanımsız) & 55 & 44.41 \\
Orman & 3 & 0.63 \\
Mera & 1 & 0.12 \\
Hevkere & 3 & 0.04 \\
\hline
\end{tabular}

\section{SONUÇLAR ve TARTIŞMA}

Taşkından etkilenen alanların öncelikle taşkın devam ederken haritalanabilmesi, kurtarma çalışmalarında veya taşkını bertaraf etme çalışmalarında, karar merciinin önceliği belirlemesi açısından önemli bilgiler içerebilir. Fakat taşkın anında kötü hava koşullarının devam etmesi, taşkın alanının yersel, İnsansız Hava Arac1 (IHA) ve optik uzaktan algilama yapan uydularla haritalanmasını imkânsız hale getirmektedir.

Bu çalışmada, her türlü hava şartında ve gecegündüz algılama yapabilen SAR uydularının taşkın alanı belirleme çalışmalarında kullanılabileceği saptanmıştır.

Ayrıca taşkın alanına ait SAM verisi olması halinde taşkın anında taşkın hacmi ve taşkın kotunun, sayısal kadastro verisi olması halinde ise taşkından sonra oluşan taşkın zararının da tespit edilebileceği sonucuna varılmıştır.

\section{KAYNAKÇA}

Autodesk Inc. (2016). Autodesk Autocad Civil 3D 2016 Help, http://help.autodesk.com/ view/ CIV3D/2016/ENU.

Canty, J.M. (2014). Image Analysis, Classification and Change Detection in Remote Sensing, with Algorithms for ENVI/IDL and Python, Third Edition. CRC Press.

Clement, M.A., Kilsby, C.G., Moore, P. (2017). Multi-temporal synthetic aperture radar flood mapping using change detection: Journal of Flood Risk Management. DOI: 10.1111/jfr3.12303.

Čotar, K., Oštir, K., Kokalj, Ž. (2016). Radar Satellite Imagery and Automatic Detection of Water Bodies. Geodetski glasnik, 50(47), 5-15.

DSİ (2016). http://www.dsi.gov.tr/haberler/2016/04 120 .

ESA (2015). Sentinel-1 Toolbox: SAR Basics Tutorial, Array Systems Computing Inc.

Henry, J.B., Chastanet, P., Fellah, K., Desnos, Y.L. (2006). Envisat multi-polarized ASAR data for flood mapping, Int. J. Remote Sens., 27, 1921-1929.

Hess, L.L., Melack, J.M., Filoso, S.; Wang, Y. (1995). Delineation of inundated area and vegetation along the Amazon floodplain with the SIR-C synthetic aperture radar, IEEE Trans. Geosci. Remote Sens., 33, 896-904. 
IECO (1966). Su Kaynaklarının Geliştirilmesi Ceyhan Havzası Projeleri, Seyhan Havzası Projeleri, Berdan Projesi, Develi Projesi, Amik Projesi, Master Plan Raporu, International Engineering Company Inc., 74 New Montgomery St. San Francisco, California, USA.

Lee, J.S. (2009). Improved Sigma Filter for Speckle Filtering of SAR Imagery, IEEE Transactions on Geoscience and Remote Sensing, Vol. 47, No. 1, 202-213.

Manjusree, P., Kumar, L.P., Bhatt, C.M., Rao, G.S., Bhanumurthy, V. (2012). Optimization of Threshold Ranges for Rapid Flood Inundation Mapping by Evaluating Backscatter Profiles of High Incidence Angle SAR Images International Journal of Disaster Risk Science, 3, 113-122. https://doi.org/10.1007/s13753-012-0011-5.

Martinis, S., Twele, A., Voigt, S. (2009). Towards operational near real-time flood detection using a split-based automatic thresholding procedure on high resolution TerraSAR-X data, Nat. Hazards Earth Syst. Sci., 9, 303314.

Onstott, R.G., Shuchman, R.A. (2004). SAR measurements of sea ice. Chapter 3, pages 81-115 in Synthetic Aperture Radar. Marine User's Manual, edited by C. R. Jackson and J. R. Apel. Washington, D.C.: National Oceanic and Atmospheric Administration

Otsu, N. (1979). A threshold selection algorithm from gray-level histograms, IEEE Trans. Syst. Man Cybern., vol. SMC-9, no. 1, pp. 62-66.

Piri Reis (1525). Kitab-1 baḥriye.

Pulvirenti, L., Pierdicca, N., Chini, M., Guerriero, L. (2011). An algorithm for operational flood mapping using Synthetic Aperture Radar (SAR) using fuzzy logic, Nat. Hazards Earth Syst. Sci., 11, 529-540.

Ramsay, W.M. (1903). Cilicia, Taurus, and the great Taurus Pass The Geographical Journal 22, 357-413.

Resmi Gazete (1969). 25 Nisan 1969/13183, Sayfa 6.

Sentinel-1 Team (2013). Sentinel-1 User Handbook. European Space Agency (ESA), Reference GMES-S1OP-EOPG-TN-13000. P:80.

Teegavarapu, R. (2012). Floods in a Changing Climate: Extreme Precipitation, International Hydrology Series, Cambridge, UK: Cambridge University Press.

USGS (2006). Shuttle Radar Topography Mission (SRTM) Finished 3-arc second, SRTM Format Documentation, Available online at:http://edc.usgs.gov/products/elevation/srt mbil.html (accessed 01/08/2006). USGS. EROS Data Center: http://edc.usgs.gov/. 